\title{
Applying DNA Metabarcoding for The Diet Investigation of The Invasive Ctenophore Mnemiopsis Leidyi in A Transitional Environment
}

\section{ANNA SCHROEDER ( $\square$ anna.schroeder@units.it )}

University of Trieste Department of Life Sciences: Universita degli Studi di Trieste Dipartimento di Scienze della Vita https://orcid.org/0000-0002-7389-6907

\section{Elisa Camatti}

ISMAR - CNR: Istituto di scienze marine Consiglio Nazionale delle Ricerche https://orcid.org/0000-00026934-9759

\section{Marco Pansera}

Stazione Zoologica Anton Dohrn Napoli

\section{Alberto Pallavicini}

Università degli Studi di Trieste Dipartimento di Biologia: Universita degli Studi di Trieste Dipartimento di Scienze della Vita

\section{Research Article}

Keywords: metabarcoding, Mnemiopsis, NIS, gut content, Venice Lagoon, feeding

Posted Date: March 7th, 2022

DOI: https://doi.org/10.21203/rs.3.rs-1307217/v1

License: (a) (1) This work is licensed under a Creative Commons Attribution 4.0 International License. Read Full License 


\section{Abstract}

Due to its potentially severe impacts on the functioning of the marine systems, the interest in understanding the ecology of invasive zooplanktivorous comb jellyfish Mnemiopsis leidyi has increased in the last decades, especially after its bloom in the Black and Caspian Sea in the late 1980s and early 1990s. In the last decade, M. leidyi has colonized most of the Mediterranean Sea, including the Adriatic Sea, and in 2016 it was firstly recorded in the Venice Lagoon (Malej et al., 2017). The impact Mnemiopsis could have especially in the Venice Lagoon as a semi-enclosed ecosystem is of concern, as it is an important nursery and foraging area for several fish species as well as an area of mussel, clam, and crab fishery and aquaculture.

While in the past, to study Mnemiopsis feeding preferences, the gut content was mainly analyzed by morphological identification, this is the first study investigating the in-situ gut contents of this species utilizing DNA metabarcoding, as it overcomes the limit in identifying partially digested prey. In this study, Mnemiopsis gut contents, collected in the Venice Lagoon, were evaluated by metabarcoding and compared to the in-situ mesozooplankton community. The results indicate that the blooming period in the late summer and that Mnemiopsis feeds on a variety of prey, mostly coinciding with the zooplankton assemblage. Notably, some groups, like decapod larvae and the slow-swimming larvae of gastropods and bivalves, appear to be favored. Conversely, the relative abundance of copepods was higher in-situ than in the gut contents.

\section{Introduction}

The increasing awareness of the potentially severe impact on the functioning of the marine systems by the invasive zooplanktivorous comb jelly Mnemiopsis leidyi (A. Agassiz 1865) (Brodeur et al. 2008), has led to a rising interest in their ecology. It is known that Mnemiopsis outbreaks can exert a top-down control

(McNamara et al. 2013) and induce trophic cascades (Roohi et al. 2010; Schneider and Behrends 1998). The invasive power of this ctenophore is favored by its high plasticity given by its tolerance to wide ranges of temperature and salinity, by the hermaphroditic reproduction (also self-fertilizing) and its regeneration ability (Purcell et al., 2001).

The bloom of M. leidyi in the Black and Caspian Sea ecosystems in the late 1980s and early 1990s became probably possible due to a shortage of predators and competitors due to overfishing (Shiganova et al. 2001). Subsequently, the blooms of Mnemiopsis have been associated with severe declines in fish stocks (Shiganova and Bulgakova 2000) and affected ecosystem production (Lynam et al. 2006).

The pressures on the ichthyoplankton community can be various: direct predation on fish eggs and larvae, as well as predation on a wide range of zooplankton it feeds on (Purcell et al. 2001), leading to an intense competition for food with zooplanktivorous fishes which may indirectly affect the abundance of ichthyoplankton. In fact, $M$. leidyi is known to feed on a variety of prey, depending on food availability and its life stage (Shiganova and Bulgakova 2000; Sullivan and Gifford 2004). Its complex feeding capacities permit to capture a wide range of zooplankton taxa and to selectively feed on i) slow-moving or immobile organisms, like mollusk and barnacle larvae or immobile eggs, collected by the cilia within the auricules creating an undetectable current which together with the mucus gets the prey to be trapped in their tentila 
(Waggett and Costello 1999; Haddock 2007; Colin et al. 2015), as well as ii) highly mobile preys, like copepods, captured by collision with the inside of the lobes (Mutlu 1999; Purcell et al. 2001; Javidpour et al. 2009). Afterwards, the prey is transported to the mouth and pharynx (Schulze-Robbecke, 1984; HernandezNicaise, 1991).

Mnemiopsis leidyi has colonized most of Mediterranean Sea, from the eastern basin to the western basin. In 2016, the invasive M. leidyi was firstly recorded in the Venice Lagoon (Malej et al. 2017), after being presumably introduced via ballast waters, a global vector in human-mediated invasions providing a fast dispersal mechanism for many marine taxa and therefore massively increasing the risk of NIS introduction (Marchini et al. 2015; Vidjak et al. 2018). In fact, the Venice Lagoon is highly impacted by human activities (Lotze et al. 2006; Solidoro et al. 2010) and a known hotspot of NIS introduction (Marchini et al. 2015; Vidjak et al. 2018; Pansera et al. 2021), due to its heavy maritime traffic. This makes it both starting point as a source of new introductions as well as continuous re-introduction via ballast waters.

As the Northern Adriatic is an important nursery and foraging area e.g., for sardines and anchovies, which together account for approximately $41 \%$ of total Adriatic marine catches (Morello and Arneri 2009; Shokralla et al. 2012), the concerns regarding the impact Mnemiopsis could have in this ecosystem are enormous, both from an ecological as well as from an economic point of view. The Northern Adriatic coast, together with the Venice Lagoon, however, is not only a vital nursery area for fishes, but it is also one of Europe's most important production areas of mussels (Mytilus) and clams (Ruditapes and Chamalea), but also an essential area of crab fishery and aquaculture. Being part of the zooplankton community as meroplankton during their larval stages, the predation on these organisms by Mnemiopsis may increase the pressure on this economic branch, both for small local businesses as well as for the industrial production. The socioeconomic functioning, however, is also affected due to the clogging of fishermen's nets and of cooling systems of power plants by high densities of Mnemiopsis (Purcell et al. 2007; Palmieri et al. 2014).

In the past, the gut content of Mnemiopsis was mainly analyzed by morphological identification to study feeding preferences. However, this approach has its limits, as it allows to identify only un- or barely digested prey, in addition to the general impediments of species identification based on morphological features for some groups like larval stages or cryptic species. DNA metabarcoding, a molecular approach based on sequencing a short DNA fragment that is unique to each species and can therefore be used for species discrimination, has been previously used for gut content analyses, e.g., on fishes (Albaina et al. 2016) or the jellyfish Chrysaora (Meredith et al. 2016). However, to the best of our knowledge, this is the first study utilizing DNA metabarcoding for gut content analyses of $M$. leidyi.

This project aims to identify by DNA metabarcoding the feeding preferences of the comb jellyfish $M$. leidyi and to speculate on its potential impact on zooplankton abundances and biodiversity. Therefore, M. leidyis feeding preferences were investigated in the Lagoon of Venice. This study will hopefully increase the knowledge about factors driving a possible decline in fish stocks, indicating if it is due to competition for zooplankton or to direct feeding of Mnemiopsis on fish eggs or larvae.

Considering the importance of this ecosystem for several meroplanktonic species, many of which are exploited commercially, the threat the feeding pressure of Mnemiopsis could have on this zooplanktonic 


\section{Material And Methods}

\section{Study site and sampling}

The study was conducted in the Venice Lagoon (VL), a Mediterranean microtidal lagoon (about $550 \mathrm{~km}^{2}$, mean depth of the tidal flats is -1.2 a.m.s.l. and reaches $-10 /-15 \mathrm{~m}$ a.m.s.l. in the natural tidal channels). It is connected through three inlets to the Northern Adriatic Sea, a shallow coastal area (mean depth of $35 \mathrm{~m}$ ) strongly influenced by the inputs of large rivers and characterized by mesotrophic conditions and by a notable spatial and temporal variability of physico-chemical and trophic gradients (Bernardi-Aubry et al. $2006,2020)$. The $V L$ is a heterogeneous system characterized by a number of environmental gradients and a mosaic of habitats (e.g., intertidal marshes and mudflats, and natural and navigation channels) that are the result of complex natural and man-induced drivers (Tagliapietra et al. 2009). With each tidal cycle, about one-third of the total volume of the lagoon is exchanged (Gačić et al. 2004), and the residence times range from a few days, in the vicinity of the inlets, to over 60 days in the inner areas (Cucco and Umgiesser 2006).

Based on morphological identification the zooplankton community in the VL is composed by about $80 \%$ of copepods (with Acartia as the most abundant genus) and by about $10 \%$ of chordates (mostly composed by Appendicularia, Ascidiacea larvae and Actinopterygii larvae or eggs), followed by echinoderms and mollusks (Camatti et al. 2008; Schroeder et al. 2020). Furthermore, it presents higher abundances of groups with more marine affinity, like cladocerans or appendicularians, in the areas nearby the inlets (Solidoro et al. 2010).

The sampling was performed as part of a study with monthly samplings of 16 stations in the Venice Lagoon from April 2018 to March 2019 (Fig. 1). Both in-situ zooplankton community and Mnemiopsis individuals were sampled using an HydroBios Apstein net with $0.4 \mathrm{~m}$ opening diameter and $200 \mu \mathrm{m}$ mesh. Moreover, environmental data, such as temperature, salinity, oxygen, turbidity and Chl-a were measured using a multiparametric CTD probe (SBE 19plus) at the sampling sites. Mnemiopsis individuals larger than $1.5 \mathrm{~cm}$ in length were measured (total biovolume $[\mathrm{ml}]$ ) and immediately frozen at $-20^{\circ} \mathrm{C}$, while zooplankton samples were preserved in $96 \%$ ethanol for genetic analyses. For the gut contents analyses, Mnemiopsis individuals were unfrozen, and the gut contents were extracted with a Pasteur pipette under a stereomicroscope (Zeiss, Discovery V8), and all gut contents within one station sample were pooled.

\section{Molecular analyses}

For the zooplankton taxonomic composition assay, from the in-situ samples, a representative subsample (about one-third of the total sample) was taken, the ethanol removed by centrifugation, and afterwards, the samples were rinsed with PBS (1x), while the extracted gut contents of Mnemiopsis were centrifuged to remove excess liquids. All samples were successively homogenized by bead-beating for one minute. Genomic DNA was extracted using the E.Z.N.A.® Mollusc DNA kit (Omega Bio-Tek) following the manufacturer's instructions and increasing the initial volume of reagents (lysis and binding buffer) provided by the kit proportionally to the sample volume. The quality and quantity of the extracted DNA were assessed 
with a NanoDrop 2000 Spectrophotometer (ThermoScientific). The amplification was performed using a degenerated forward primer jdgLC01490 (5'-TCAACAAAYCAYAARGAYATYGG-3') (Schroeder et al., 2021) in combination with the reverse internal primer mICOlintR proposed by Leray et al. (2013) with a target length of $319 \mathrm{bp}$. The reverse primer mICOlintR was slightly modified compared to the original to match the forward internal primer mICOlintF by interchanging the "S" with "W" nucleotides: 5 '-

GGRGGRTAWACWGTTCAWCCWGTWCC-3' instead of 5'-GGRGGRTASACSGTTCASCCSGTSCC-3'. As shown by Schroeder et al. (2021), this primer pair performed well for zooplankton biodiversity assessments and was chosen for this study due to its impediments in amplifying ctenophores. In this way, it could be made sure, to not primarily amplify the host DNA, but rather the actual gut content.

The amplification was performed as by Schroeder et al. (2021). Briefly, we performed a two-step PCR, after the secondary PCR, where the sample-tags were bound, the library was purified, quantified and prepared for HTS by pooling an equimolar amount of amplicon products. Emulsion PCR was conducted using the lon One Touch System (Life Technologies) following the manufacturer's recommendations, and DNA was bound to Ion Sphere particles (Life Technologies) for clonal amplification automatically enriched with the lon OneTouch ES system (Life Technologies). For sequencing, the library was loaded on a $316^{\mathrm{Tm}}$ chip with 650 flows in a PGM (Life Technologies).

\section{Bioinformatics and statistics}

The bioinformatic workflow was conducted following Schroeder et al. (2021), including sequence preparation (filtering and trimming), error corrections, chimera removal and several steps of taxonomic assignment. Those steps included assignments against a COI reference database of marine metazoan sequences deposited in GenBank following the query used by Schroeder et al. (2020) at a $97 \%$ and $94 \%$ similarity threshold, as well as recovery of putative metazoan sequences by clustering $85 \%$ similarity hits denovo at 97\% (q2-vsearch (Rognes et al. 2016)), comparing those OTUs against the GenBank database with BlastN+ (Camacho et al. 2009), joining the metazoan taxonomy with a BLASTn p-identity of at least $94 \%$ to the final dataset and considering OTUs with a BLASTn p-identity of $<94 \%$ and $>90 \%$ as a "best match", hence OTUs with low taxonomic confidentiality (see Schroeder et al., 2021).

Spatial and temporal patterns of the environmental factors based on Euclidean distances of normalized data were assessed using repeated-measure permutational analysis of variance (PERMANOVA) with the sampling months as fixed factor and the stations as a random factor (PRIMER $6+$ and PERMANOVA software package; PRIMER-E, Ltd., UK), and to visualize the similarities between the samples in terms of environmental conditions a PCoA (Principal coordinates analysis). With the R software (R Core Team, 2018), differences between months and stations were tested by the Kruskal-Wallis test, while Pearson's correlations were calculated between biovolume $\left[\mathrm{ml} / \mathrm{m}^{3}\right]$ and environmental parameters. The Pearson's correlations between the in-situ zooplankton community and Mnemiopsis'gut content were also calculated for groups at the different taxonomic levels as well as for the most abundant species (square-root transformed percentages). Beta diversity was calculated from dissimilarity matrices built according to Bray-Curtis distances using the metaMDS script with the autotransform function (R package vegan) (Oksanen et al. 2019) and plotted colored by season and by location, where the stations were grouped by location "inner" and "med" and "inlet" stations, based on residence time. 


\section{Results}

\section{Environmental characteristics}

The environmental parameters differ significantly both temporally and spatially (Fig. 2a, Table 1). The temporal pattern follows a temperature gradient, a parameter that shows especially high variability owed to the general low depths in the Venice Lagoon, ranging from 3.0 to $30.5^{\circ} \mathrm{C}\left(18.3^{\circ} \mathrm{C} \pm 8.2\right)$ and exhibit the typical seasonal trend $\left(\mathrm{KW}: \mathrm{chi}^{2}=180.63, \mathrm{df}=11, \mathrm{p}<2.2 \mathrm{e}-16\right)$. In the months with lower temperature values, $\mathrm{Chl}-\mathrm{a}$ is also lower, ranging from 0.7 to $49.3 \mathrm{ug} / \mathrm{l}(5.1 \mathrm{ug} / \mathrm{l} \pm 6.9)$. In contrast, turbidity and salinity are more related to the location, with higher salinities $\left(\mathrm{KW}: \mathrm{chi}^{2}=122.54, \mathrm{df}=15, \mathrm{p}<2.2 \mathrm{e}-16\right)$ and lower turbidity values $\left(K W:\right.$ chi $\left.^{2}=112.7, d f=15, p<2.2 e-16\right)$ in the inlet stations $(4,11$ and 15$)$ and the nearby areas (Fig. 2b). Overall, the salinity values ranged from 9.0 to $36.3(30.9 \pm 4.2)$, the turbidity from 0.8 to $38.5 \mathrm{NTU}(6.3 \mathrm{NTU} \pm 5.6)$ and the oxygen from 56.9 to $188.2 \%(102.3 \% \pm 17.4)$.

Table 1

Spatial and temporal patterns of the environmental factors based on Euclidean distances assessed using repeated-measure PERMANOVA with the sampling months as fixed factor and the stations as random factor.

\begin{tabular}{|llllllll|}
\hline & df & SS & MS & Pseudo-F & P(perm) & Unique perms \\
\hline month & 11 & 344.88 & 31.4 & 14.7 & 0.001 & 996 \\
\hline station & 15 & 257.98 & 17.2 & 8.1 & 0.001 & 995 \\
\hline Res & 165 & 352.14 & 2.1 & & & \\
\hline Total & 191 & 955 & & & & \\
\hline
\end{tabular}

\section{Biovolume of Mnemiopsis leidyi}

During the study period, the first individuals of M. leidyi were detected in June 2018 including larval stages ( $0.5 \mathrm{~cm}$ length). Individuals larger than $1.5 \mathrm{~cm}$ length were found in 44 samples, from June to February, with variable total biovolume ranging from 1.3 to $78 \mathrm{ml} / \mathrm{m}^{3}$ (Fig. 3a). Still, the highest biovolumes $\left[\mathrm{ml} / \mathrm{m}^{3}\right]$ of Mnemiopsis were found during late summer, especially from July to October (Fig. 3b). From November, the presence was significantly reduced, and only single individuals were detected in the samples, and the presence of larval stages increased again. In fact, temperature shows a weak, but significant positive correlation to the biovolume of Mnemiopsis $(t=3.55, d f=190, p=0.0005$, cor $=0.25$ ), while none of the other environmental parameters show significant correlations. Also, the abundance differed between stations and seemed to show slightly lower values close to the inlets (Fig. 3c).

\section{Mnemiopsis' diet}

The number of raw sequences was $2.3 \times 10^{6}$ reads for the 44 samples of Mnemiopsis gut content and $3.2 \times$ $10^{6}$ reads for the 44 samples of in-situ mesozooplankton samples. After taxonomic assignments, the final number of sequences of the gut contents of Mnemiopsis was 768,611 (assignments at $97 \%$ : $71.1 \%$; at $94 \%$ : $14.9 \%$; by the recovery of putative metazoans: $14 \%$ ) distributed between 122 OTUs, and of the 
mesozooplankton community, 233 OTUs representing 1,486,969 sequences (assignments at 97\%: 87.5\%; at 94\%: $9.3 \%$; by the recovery of putative metazoans: $3.2 \%$ ). Except for the beta-diversity estimates the most stringent dataset was used for the following analyses by excluding the "best match" assignments, thus, those OTUs with low taxonomic confidentiality. This approach resulted in a stringent dataset of 107 OTUs with 672,956 sequences of Mnemiopsis gut content and 213 OTUs with 1,464,823 sequences of in-situ mesozooplankton.

The taxonomic assignment of the gut content of Mnemiopsis indicates that it feeds on a variety of prays. The most abundant phylum of pray are arthropods with a mean of $62 \%$ (SD 31.37), with the copepod order Calanoida as the most represented group $(25 \% \pm 25)$, followed by the classes of Decapoda $(20 \% \pm 30)$ and Branchiopoda (composed by cladocerans only) $(12 \% \pm 26)$. The second most abundant phylum is Mollusca $(21 \% \pm 27)$, composed mainly by Gastropoda $(15 \% \pm 23)$ and Bivalvia $(5 \% \pm 10)$; the third is Annelida (composed by polychaetes only) $(12 \% \pm 23)$, and the fourth is Nemertea $(3 \% \pm 6)$. However, the high values of standard deviation indicate a high variability between the samples (Fig. 4, Table 2).

The in-situ mesozooplankton community shows comparable compositions. Several groups show significant correlations between the gut content and the in-situ mesozooplankton community: Cladocera, Cyclopoida, Amphipoda, Decapoda, Bryozoa, Anthozoa, Hydrozoa and Nemertea (Table 2). However, there are some differences: the relative abundance of arthropods is higher ( $89 \%$ compared to $62 \%$ ), with higher proportions of calanoids ( $59 \%$ vs. $25 \%$ ) and cladocerans ( $21 \%$ vs. $12 \%$ ), but lower relative abundances of decapods ( $5 \%$ vs. $20 \%$ ), indicating a preference of Mnemiopsis of the latter one. Also, mollusks ( $3 \%$ vs. $21 \%$ ), Nemertea $(0.02 \%$ vs. $3 \%)$ and Polychaeta ( $1 \%$ vs. $12 \%)$ seem to be preferred.

Regarding the relative abundances of the four most abundant copepod genera in the gut content of Mnemiopsis (relative abundance calculated in relation to copepods), the genus Acartia contributed with $71.9 \%$ to the copepod community, followed by Centropages with $7.1 \%$, Oithona with $6.6 \%$ and Paracalanus with $3.4 \%$, while in the zooplankton community Acartia was again at the first rank with $76.9 \%$, followed by Paracalanus with $8.2 \%$, by Centropages with $5.6 \%$ and by Temora with $3.5 \%$. The species Acartia tonsa, Centropages ponticus, and Paracalanus spp. show similar distribution between the in-situ zooplankton community and the gut content (Fig. 5a, b). Temora stylifera and the cladocerans Penilia avirostris are more abundant in-situ, indicating a reduced capture by Mnemiopsis, while Acartia clausii, Oithona nana and Euterpina acutifrons are more abundant in the gut content, suggesting a possible preferential feeding by Mnemiopsis of the latter three (Fig. 5a, b, c). Especially several meroplanktonic taxa seem to accumulate in Mnemiopsis' gut, such as mollusk larvae (Fig. 5c), e.g., the bivalve Ruditapes philippinarum, a species of immense commercial interest in the VL, as well as the larvae of the crabs Carcinus aestuarii and Dyspanopeus sayi, polychaete larvae and the nemertean Cephalothrix sp. (Fig. 5d). 
Table 2

Mean values and standard deviation of taxonomic composition of the gut contents and the in-situ mesozooplankton community and its correlations (based on square-root transformed data).

\begin{tabular}{|c|c|c|c|c|c|c|c|c|c|}
\hline \multirow[t]{2}{*}{ taxon } & \multirow[t]{2}{*}{ level } & \multicolumn{2}{|c|}{ Mnemiopsis gut } & \multicolumn{2}{|c|}{$\begin{array}{l}\text { Zooplankton } \\
\text { community }\end{array}$} & \multicolumn{4}{|c|}{ Pearson correlation $(\mathrm{DF}=42)$} \\
\hline & & $\begin{array}{l}\text { mean } \\
\text { [\%] }\end{array}$ & SD & $\begin{array}{l}\text { mean } \\
\text { [\%] }\end{array}$ & SD & $\mathbf{r}$ & $\mathrm{t}$ & $\mathbf{p}$ & Sign. \\
\hline Annelida & $\mathrm{p}$ & 11.68 & 22.80 & 0.89 & 2.25 & 0.196 & 1.30 & 0.201 & \\
\hline Arthropoda & $\mathrm{p}$ & 61.66 & 31.37 & 89.08 & 17.54 & 0.209 & 1.39 & 0.173 & \\
\hline Branchiopoda & c & 12.39 & 25.82 & 20.81 & 29.01 & 0.720 & 6.73 & $\begin{array}{l}3.5 \mathrm{e}- \\
08\end{array}$ & $\star \star \star *$ \\
\hline Hexanauplia & c & 29.52 & 26.65 & 63.63 & 30.17 & 0.407 & 2.89 & 0.006 & \\
\hline Calanoida & 0 & 24.96 & 24.80 & 58.64 & 29.52 & 0.412 & 2.93 & 0.0054 & \\
\hline Cyclopoida & o & 0.46 & 1.41 & 0.49 & 1.51 & 0.617 & 5.08 & $\begin{array}{l}8.26 e^{-} \\
06\end{array}$ & $\star \star \star ~$ \\
\hline Harpacticoida & 0 & 0.20 & 0.48 & 0.92 & 2.96 & 0.130 & 0.85 & 0.399 & \\
\hline Poecilostomatoida & o & 0.41 & 1.30 & 0.02 & 0.05 & 0.234 & 1.56 & 0.126 & \\
\hline Sessilia & 0 & 3.49 & 11.63 & 3.56 & 5.81 & 0.441 & 3.18 & 0.003 & * \\
\hline Malacostraca & c & 19.75 & 29.66 & 4.64 & 7.81 & 0.522 & 3.97 & 0.0003 & $\star \star \star ~$ \\
\hline Amphipoda & o & 0.01 & 0.06 & 0.08 & 0.16 & 0.536 & 4.12 & 0.0002 & 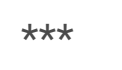 \\
\hline Decapoda & o & 19.74 & 29.67 & 4.55 & 7.76 & 0.564 & 4.43 & $\begin{array}{l}6.6 \mathrm{e}- \\
05\end{array}$ & $\star \star \star$ \\
\hline Mysida & o & 0.00 & 0.00 & 0.01 & 0.05 & - & - & - & - \\
\hline Bryozoa & $\mathrm{p}$ & 0.001 & 0.01 & 0.04 & 0.15 & 0.865 & 11.15 & $\begin{array}{l}3.9 \mathrm{e}- \\
14\end{array}$ & $\star \star \star$ \\
\hline Chaetognatha & $\mathrm{p}$ & 0.09 & 0.25 & 0.13 & 0.28 & 0.405 & 2.87 & 0.006 & \\
\hline Chordata & $\mathrm{p}$ & 0.08 & 0.23 & 3.10 & 13.52 & -0.166 & -1.09 & 0.283 & \\
\hline Actinopterygii & c & 0.07 & 0.22 & 3.09 & 13.52 & -0.140 & -0.92 & 0.365 & \\
\hline Ascidiacea & c & 0.01 & 0.07 & 0.02 & 0.05 & -0.050 & -0.33 & 0.746 & \\
\hline Cnidaria & $\mathrm{p}$ & 1.52 & 5.35 & 2.14 & 5.06 & 0.462 & 3.37 & 0.002 & * \\
\hline Anthozoa & c & 0.0001 & 0.0006 & 0.79 & 3.91 & 0.803 & 8.72 & $\begin{array}{l}5.7 e^{-} \\
11\end{array}$ & $\star \star *$ \\
\hline Hydrozoa & c & 1.43 & 5.35 & 1.31 & 2.41 & 0.516 & 3.90 & 0.0003 & 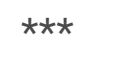 \\
\hline Scyphozoa & c & 0.09 & 0.33 & 0.03 & 0.09 & 0.340 & 2.35 & 0.024 & * \\
\hline Echinodermata & $\mathrm{p}$ & 1.53 & 8.47 & 0.90 & 3.44 & 0.019 & 0.125 & 0.901 & \\
\hline
\end{tabular}




\begin{tabular}{|c|c|c|c|c|c|c|c|c|c|}
\hline \multirow[t]{2}{*}{ taxon } & \multirow[t]{2}{*}{ level } & \multicolumn{2}{|c|}{ Mnemiopsis gut } & \multicolumn{2}{|c|}{$\begin{array}{l}\text { Zooplankton } \\
\text { community }\end{array}$} & \multicolumn{4}{|c|}{ Pearson correlation (DF=42) } \\
\hline & & $\begin{array}{l}\text { mean } \\
{[\%]}\end{array}$ & SD & $\begin{array}{l}\text { mean } \\
\text { [\%] }\end{array}$ & SD & $\mathbf{r}$ & $t$ & p & Sign. \\
\hline Gastrotricha & $\mathrm{p}$ & 0.00 & 0.00 & 0.0003 & 0.002 & - & - & - & - \\
\hline Mollusca & $\mathrm{p}$ & 20.52 & 26.73 & 2.80 & 5.36 & 0.128 & 0.834 & 0.409 & \\
\hline Bivalvia & c & 5.35 & 10.26 & 0.98 & 2.92 & 0.094 & 0.61 & 0.543 & \\
\hline Cephalopoda & c & 0.00 & 0.00 & 0.0003 & 0.002 & - & - & - & - \\
\hline Gastropoda & c & 15.17 & 22.92 & 1.83 & 3.67 & 0.242 & 1.61 & 0.114 & \\
\hline Scaphopoda & c & 0.00 & 0.00 & 0.0003 & 0.002 & - & - & - & - \\
\hline Nematoda & $\mathrm{p}$ & 0.00 & 0.00 & 0.01 & 0.03 & - & - & - & - \\
\hline Nemertea & $\mathrm{p}$ & 2.81 & 6.47 & 0.02 & 0.05 & 5.39 & 4.14 & 0.0002 & 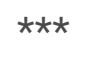 \\
\hline Phoronida & $\mathrm{p}$ & 0.00 & 0.00 & 0.002 & 0.01 & - & - & - & - \\
\hline Porifera & $\mathrm{p}$ & 0.11 & 0.41 & 0.87 & 3.14 & 0.013 & 0.083 & 0.935 & \\
\hline
\end{tabular}

The beta-diversity analyses, based in the most inclusive dataset, hence including also the "best match" assignments in order to include as many putative metazoan OTUs as possible, resulted in a clear temporal differentiation by seasons as well as a spatial one by location for both the zooplankton community and the gut contents (Fig. 6a). However, the differences between the zooplankton samples are greater than between gut content samples (Fig. 6b). When computing a Bray-Curtis matrix for both datasets together and plotting them on a single NMDS plot (Fig. 6c), it emerges that the two datasets are almost overlapping rather than creating two different clusters. This overlap indicates that the feeding of Mnemiopsis depends mainly on the food available at that specific moment and location.

\section{Discussion}

Understanding the characteristics of blooms of the zooplanktivorous invasive predator M. leidyi is increasingly important, due to its ongoing successful invasion of new regions and its potential impact on zooplankton densities and ecosystem production. The top-down effect of the predation pressure on zooplankton, which is especially significant during intense blooms of $M$. leidyi, can favor a substantial decrease in zooplankton and a correlated increase in phytoplankton (Shiganova 1998; Finenko et al. 2006; Tiselius and Møller 2017), accompanied by a decline in fish stocks, as already experienced in the Black and Caspian Seas (Shiganova and Bulgakova 2000).

Considering the importance of Venice Lagoon as a nursery area, the massive blooms experienced in the last years in this habitat raise concerns regarding its already ongoing and future effects on ecosystem production and ecosystem services. Hence, given the importance of this area within the "blue economy" with various business categories falling under this definition, such as environmental regulation, fish farming and 
fishing, providing additional insights into the potential impact of invasive species on the ecosystem, on which also human activities gravitate, is crucial to reduce the gap between economic demand and environmental protection.

In this study, Mnemiopsis was found to be present at all 16 investigated stations in the Venice Lagoon, which are representative of different environmental conditions and showed a seasonal persistence (at different life stages), hence tolerating the measured temperature range of $3.0-30.5^{\circ} \mathrm{C}$. These findings confirm its high ecological plasticity, which makes it a successful invader and highlights the need to improve our knowledge about this species, including its feeding preference. Spatial differences in abundance found within the lagoon may be driven not only by prey availability, but also by hydrodynamic processes that accumulate $M$. leidyi in specific areas. Seasonal differences are evident with highest abundances in terms of biovolume $\left[\mathrm{ml} / \mathrm{m}^{3}\right]$ detected during summer (July-October) with temperature as the main abiotic driver, likewise stated by many authors, e.g., Kremer (1994), who mentioned temperature and prey abundance as key factors affecting its seasonal patterns. Other factors that make semi-enclosed lagoons especially vulnerable are potential low oxygen levels that can occure especially during summer (Bernardi-Aubry et al. 2020). However, M. leidyi, as other gelatinous species, can potentially benefit from it as they are generally more tolerant to hypoxia compared to their preys. Decker et al. (2004) showed a reduced jumping frequency of the copepod $A$. tonsa favoriting capture rates as it makes less-tolerant prey more vulnerable to predation in hypoxic waters.

Several authors have studied the feeding preferences of $M$. leidyi in the past. However, to our knowledge, this is the first study applying DNA metabarcoding based on NGS technologies to investigate its dietary composition. The primary benefit of this method compared to morphology-based identification in analyzing the feeding preference is the detection of also partially digested prey and cryptic species. However, the (relative) quantification of prey items that are more effortlessly digestible, e.g., soft organisms like fish larvae, or that have been ingested beforehand, may be underestimated.

The literature, with morphology-based identification, indicates that $M$. leidyis diet often reflects the composition of ambient preys (e.g., Javidpour et al. 2009; Madsen and Riisgård 2010; Granhag et al. 2011). Copepods are often dominating the diet of $M$. leidyi, but also meroplanktonic larvae of polychaetes, mollusks, decapods and barnacles are fed (e.g., Kremer 1979; Purcell et al. 2001; Colin et al. 2015). In our study, the diet of $M$. leidyi was very variable, but mainly included copepods, decapods, cladocerans, gastropods, bivalves and polychaetes, but also echinoderms, Nemertea and cnidarians, hence a composition that characterizes a typical lagoon community. During winter, the dietary composition shows a peak in polychaete larvae, in consistency with Larson (1987) and McNamara et al. (2010), which reported the ingestion of polychaetes larvae by Mnemiopsis. However, this noticeable difference of the winter samples may also be a result of higher uncertainty due to the smaller sample size (see biovolume during winter).

Similarly to Decker et al. (2004) and Roohi et al. (2010), also in our study A. tonsa was the most abundant copepod species, both in-situ and in the gut content. However, in general, copepods and cladocerans were less represented in the gut content than in-situ, while decapod and mollusk larvae were more abundant in the gut content, indicating a preferential feeding on the latter ones. In fact, due to the capture mechanisms of 
Mnemiopsis, less mobile organisms such as mollusks seemed to be a very vulnerable prey of $M$. leidyi, which is consistent with the literature (e.g., Madsen and Riisgård 2010; Marchessaux et al. 2021).

Nevertheless, species-specific differences in mobility are of importance as well. Within copepods, for example, smaller species like Oithona nana and 0 . davisae or Euterpina acutifrons seemed to be captured preferentially. In comparison, the larger species Temora stylifera, being potentially faster, are less abundant in the gut content as they may escape from M. leidyi more easily. It has to be kept in mind, especially regarding the holoplanktonic copepods, that DNA metabarcoding does not allow to differentiate between life stages. Therefore, more than size differences between copepods species, the actual life stage of each species at that specific moment may have a more significant effect on the vulnerability of particular species to the feeding pressure of $M$. leidyi. The diet of Mnemiopsis is known to differ at different life stages. While larvae and post-larvae consume primarily microphyto- and microzooplankton prey like dinoflagellates or ciliates (Sullivan and Gifford 2004), adults feed on a variety of holo- and meroplankton organisms (Shiganova and Bulgakova 2000). In this study, a standard sampling net with a mesh size of $200 \mu \mathrm{m}$ was used to collect the in-situ zooplankton community. The ingested preys may include zooplankton smaller than $200 \mu \mathrm{m}$, like nauplii or bivalve larvae, which might be underestimated in the sampled zooplankton community. However, as in this study, only adult Mnemiopsis individuals above $1.5 \mathrm{~cm}$ were included in the gut content analysis, the use of a standard mesozooplankton net with a mesh size of $200 \mu \mathrm{m}$ should not have a strong bias of the comparison of the in-situ zooplankton community with the gut content. The selectivity of the $200 \mu \mathrm{m}$ sampling net could be another explanation for the higher relative abundance of small sized organisms in the gut content compared to the in-situ zooplankton assemblages. Hence, the additional use of e.g., an $80 \mu \mathrm{m}$ plankton net to better describe the smaller size fraction of the community could be beneficial (Pansera et al., 2014).

As previously mentioned, the VL represents an ecosystem of huge ecological but especially socio-economic importance. It is not only a vitalnursery area for fishes, but it is also an area for mussel, clam and crab aquaculture. On the one hand, in this study, no significant correlation between the in-situ abundance of fish larvae or eggs and its abundance the gut content was found, indicating no direct predation on fish larvae or eggs. This is probably explained by the dominance of benthic fish species in the VL, like Zosterisessor ophiocephalus, and the fact that the spawning time may not coincide with the major blooming period of Mnemiopsis (Franzoi et al. 2010). Moreover, the reproductive strategy of lagoon resident fish species is adapted to prevent seaward flushing of eggs and larvae by spawning demersal eggs attached to the aquatic vegetation or other substrates, while the planktonic larval stage is reduced or lacking (Dando 1984). Therefore, rather than direct predation on fish eggs and larvae, competition for zooplankton may have an impact on the fish stock in the $\mathrm{VL}$, where socio-economic functioning is also affected by the clogging of fishermen's nets by Mnemiopsis (Palmieri et al. 2014). On the other hand, the impact Mnemiopsis seems to have on the meroplanktonic compartment of the zooplankton community may increase the pressure on the local economy and industrial production. In fact, while in other geographic areas the major concern regarding the arrival and large blooming of Mnemiopsis refers mainly to the fish stocks and its associated economy, in the VL and the Northern Adriatic coasts, Mnemiopsis' impact may be greater on the meroplanktonic compartment, hence on the mussel, clam, and crab fishery and aquaculture. 


\section{Declarations}

\section{Acknowledgments}

This study is based on a monitoring program within LTER-ITALY (Italian Long-Term Ecological Research Network) that we wish to acknowledge. A.S. was supported by the joint PhD Program "Environmental Life Sciences" of the University of Trieste and the University of Udine co-financed by the National Research Council, Institute of Marine Sciences (CNR ISMAR). The authors wish to thank F. Bernardi Aubry, G. Zennaro and L. Dametto for the technical support during sampling, D. Stanković for its bioinformatics support and F. Gionechetti and the whole team of the Laboratory of Applied and Comparative Genomics at the University of Trieste.

\section{Declaration of interest}

none

\section{CRediTs}

Conceptualization: Camatti E., Pallavicini A., Schroeder A., Pansera M.; Formal analysis and investigation: Schroeder A., Pansera M.; Writing - original draft preparation: Schroeder A.; Writing - review and editing: Camatti E., Pallavicini A., Pansera M., Schroeder A.; Funding acquisition: Camatti E., Pallavicini A.

\section{References}

1. Albaina A, Aguirre M, Abad D, et al (2016) 18S rRNA V9 metabarcoding for diet characterization: $A$ critical evaluation with two sympatric zooplanktivorous fish species. Ecol Evol 6:1809-1824. https://doi.org/10.1002/ece3.1986

2. Bernardi-Aubry F, Acri F, Bastianini M, et al (2006) Seasonal and interannual variations of phytoplankton in the Gulf of Venice (Northern Adriatic Sea). Chem Ecol 22:. https://doi.org/10.1080/02757540600687962

3. Bernardi-Aubry F, Acri F, Scarpa GM, Braga F (2020) Phytoplankton - Macrophyte Interaction in the Lagoon. Water 12:2810

4. Brodeur RD, Decker MB, Ciannelli L, et al (2008) Rise and fall of jellyfish in the eastern Bering Sea in relation to climate regime shifts. Prog Oceanogr 77:103-111. https://doi.org/10.1016/j.pocean.2008.03.017

5. Camacho C, Coulouris G, Avagyan V, et al (2009) BLAST+: Architecture and applications. BMC Bioinformatics 10:1-9. https://doi.org/10.1186/1471-2105-10-421

6. Camatti E, Comaschi A, De Olazabal A, Fonda Umani S (2008) Annual dynamics of the mesozooplankton communities in a highly variable ecosystem (North Adriatic Sea, Italy). Mar Ecol 29:387-398. https://doi.org/10.1111/j.1439-0485.2008.00256.x 
7. Colin SP, MacPherson R, Gemmell B, et al (2015) Elevating the predatory effect: Sensory-scanning foraging strategy by the lobate ctenophore Mnemiopsis leidyi. Limnol Oceanogr 60:100-109. https://doi.org/10.1002/Ino.10007

8. Cucco A, Umgiesser G (2006) Modeling the Venice Lagoon residence time. Ecol Modell 193:34-51. https://doi.org/10.1016/j.ecolmodel.2005.07.043

9. Dando PR (1984) Reproduction in estuarine fish. In: Potts GW, Wootton RJ (eds) Fish Reproduction: strategies and tactics. Academic Press, London, pp 155-170

10. Decker MB, Breitburg DL, Purcell JE (2004) Effects of low dissolved oxygen on zooplankton predation by the ctenophore Mnemiopsis leidyi. Mar Ecol Prog Ser 280:163-172. https://doi.org/10.3354/meps280163

11. Finenko GA, Kideys AE, Anninsky BE, et al (2006) Invasive ctenophore Mnemiopsis leidyi in the Caspian Sea: Feeding, respiration, reproduction and predatory impact on the zooplankton community. Mar Ecol Prog Ser 314:171-185. https://doi.org/10.3354/meps314171

12. Franzoi P, Franco A, Torricelli P (2010) Fish assemblage diversity and dynamics in the Venice lagoon. Rend Lincei 21:269-281. https://doi.org/10.1007/s12210-010-0079-z

13. Gačić M, Mancero Mosquera I, Kovačević V, et al (2004) Temporal variations of water flow between the Venetian lagoon and the open sea. J Mar Syst 51:33-47. https://doi.org/10.1016/j.jmarsys.2004.05.025

14. Granhag L, Møller LF, Hansson LJ (2011) Size-specific clearance rates of the ctenophore Mnemiopsis leidyi based on in situ gut content analyses. J Plankton Res 33:1043-1052. https://doi.org/10.1093/plankt/fbr010

15. Haddock SHD (2007) Comparative feeding behavior of planktonic ctenophores. Integr Comp Biol 47:847-853. https://doi.org/10.1093/icb/icm088

16. Hernandez-Nicaise ML (1991) Ctenophora. In Microscopic Anatomy of Invertebrates, Vol. 2. Placozoa, Porifera, Cnidaria, and Ctenophora. 456

17. Javidpour J, Molinero JC, Lehmann A, et al (2009) Annual assessment of the predation of Mnemiopsis leidyi in a new invaded environment, the Kiel Fjord (Western Baltic Sea): A matter of concern? J Plankton Res 31:729-738. https://doi.org/10.1093/plankt/fbp021

18. Kremer P (1979) Predation by the ctenophore Mnemiopsis leidyi in Narragansett Bay, Rhode Island. Estuaries 2:97-105. https://doi.org/10.2307/1351633

19. Larson RJ (1987) In Situ Feeding Rates of the Ctenophore Mnemiopsis mccrady. Estuaries and Coasts 10:87-91

20. Lotze HK, Lenihan HS, Bourque BJ, et al (2006) Depletion, Degradation, and Recovery Potential of Estuaries and Coastal Seas. Science (80-) 312:1806 LP - 1809. https://doi.org/10.1126/science.1128035

21. Lynam CP, Gibbons MJ, Axelsen BE, Sparks CA, Coetzee J, Heywood BG, Brierley AS (2006) Jellyfish overtake fish in a heavily fished ecosystem. Current biology, 16(13), R492-R493.

22. Madsen CV, Riisgård HU (2010) Ingestion-rate method for measurement of clearance rates of the ctenophore Mnemiopsis leidyi. Aquat Invasions 5:357-361. https://doi.org/10.3391/ai.2010.5.4.04 
23. Malej A, Tirelli V, Lučić D, et al (2017) Mnemiopsis leidyi in the northern Adriatic: here to stay? J Sea Res 124:10-16. https://doi.org/10.1016/j.seares.2017.04.010

24. Marchessaux G, Belloni B, Gadreaud J, Thibault D (2021) Predation assessment of the invasive ctenophore Mnemiopsis leidyi in a French Mediterranean lagoon. J Plankton Res 43:161-179. https://doi.org/10.1093/plankt/fbab002

25. Marchini A, Ferrario J, Sfriso A, Occhipinti-Ambrogi A (2015) Current status and trends of biological invasions in the Lagoon of Venice, a hotspot of marine NIS introductions in the Mediterranean Sea. Biol Invasions 17:2943-2962. https://doi.org/10.1007/s10530-015-0922-3

26. McNamara ME, Lonsdale DJ, Cerrato RM (2013) Top-down control of mesozooplankton by adult Mnemiopsis leidyi influences microplankton abundance and composition enhancing prey conditions for larval ctenophores. Estuar Coast Shelf Sci 133:2-10. https://doi.org/10.1016/j.ecss.2013.04.019

27. McNamara ME, Lonsdale DJ, Cerrato RM (2010) Shifting abundance of the ctenophore Mnemiopsis leidyi and the implications for larval bivalve mortality. Mar Biol 157:401-412. https://doi.org/10.1007/s00227-009-1327-6

28. Meredith RW, Gaynor JJ, Bologna PAX (2016) Diet assessment of the Atlantic Sea Nettle Chrysaora quinquecirrha in Barnegat Bay, New Jersey, using next-generation sequencing. Mol Ecol 25:6248-6266. https://doi.org/10.1111/mec.13918

29. Morello EB, Arneri E (2009) Anchovy and sardine in the Adriatic Sea - an ecological review. In: Gibson RN, Atkinson RJA, Gordon JDM (Eds.), Oceanography and Marine Biology. An Annual Review. 47. pp. 209-256

30. Mutlu E (1999) Distribution and abundance of ctenophores and their zooplankton food in the Black Sea. II. Mnemiopsis leidyi. Mar Biol 135:603-613. https://doi.org/10.1007/s002270050661

31. Oksanen J, Blanchet FG, Friendly M, et al (2019) Package "vegan"- Community ecology package. CRAN

32. Palmieri MG, Barausse A, Luisetti T, Turner K (2014) Jellyfish blooms in the Northern Adriatic Sea: Fishermen's perceptions and economic impacts on fisheries. Fish Res 155:51-58. https://doi.org/10.1016/j.fishres.2014.02.021

33. Pansera M, Granata A, Guglielmo L, Minutoli R, Zagami G, Brugnano C (2014) How does mesh-size selection reshape the description of zooplankton community structure in coastal lakes? Estuarine, Coastal and Shelf Science, 151, 221-235

34. Pansera M, Camatti E, Schroeder A, et al (2021) The non-indigenous Oithona davisae in a Mediterranean transitional environment: coexistence patterns with competing species. Sci Rep 11:1-14. https://doi.org/10.1038/s41598-021-87662-5

35. Purcell JE, Shiganova TA, Decker MB, Houde ED (2001) The ctenophore Mnemiopsis in native and exotic habitats: U.S. estuaries versus the Black Sea basin. Hydrobiologia 451:145-176. https://doi.org/10.1023/A:1011826618539

36. Purcell JE, Uye SI, Lo WT (2007) Anthropogenic causes of jellyfish blooms and their direct consequences for humans: A review. Mar Ecol Prog Ser 350:153-174. https://doi.org/10.3354/meps07093 
37. Rognes T, Flouri T, Nichols B, et al (2016) VSEARCH: A versatile open source tool for metagenomics. PeerJ 2016:1-22. https://doi.org/10.7717/peerj.2584

38. Roohi A, Kideys AE, Sajjadi A, et al (2010) Changes in biodiversity of phytoplankton, zooplankton, fishes and macrobenthos in the Southern Caspian Sea after the invasion of the ctenophore Mnemiopsis leidyi. Biol Invasions 12:2343-2361. https://doi.org/10.1007/s10530-009-9648-4

39. Schneider G , Behrends G (1994) Population dynamics and the trophic role of Aurelia aurita medusae in the Kiel Bight and western Baltic. ICES Journal ofMarine Science 51, 359-367

40. Schulze-Robbecke AC (1984) Functional morphology of Bolinopsis infundibulum (Ctenophora). HelgoländerMeeresun., 38, 47-64

41. Schroeder A, Pallavicini A, Edomi P, et al (2021) Suitability of a dual COI marker for marine zooplankton DNA metabarcoding. Mar Environ Res 170:105444. https://doi.org/10.1016/j.marenvres.2021.105444

42. Schroeder A, Stanković D, Pallavicini A, et al (2020) DNA metabarcoding and morphological analysis Assessment of zooplankton biodiversity in transitional waters. Mar Environ Res 160:. https://doi.org/10.1016/j.marenvres.2020.104946

43. Shiganova TA (1998) Invasion of the Black Sea by the ctenophore Mnemiopsis leidyi and recent changes in pelagic community structure. Fish Oceanogr 7:305-310. https://doi.org/10.1046/j.13652419.1998.00080.x

44. Shiganova TA, Bulgakova Y V. (2000) Effects of gelatinous plankton on Black Sea and Sea of Azov fish and their food resources. ICES J Mar Sci 57:641-648. https://doi.org/10.1006/jmsc.2000.0736

45. Shiganova TA, Mirzoyan ZA, Studenikina EA, et al (2001) Population development of the invader ctenophore Mnemiopsis leidyi, in the Black Sea and in other seas of the Mediterranean basin. Mar Biol 139:431-445. https://doi.org/10.1007/s002270100554

46. Shokralla S, Spall JL, Gibson JF, Hajibabaei M (2012) Next-generation sequencing technologies for environmental DNA research. Mol Ecol 21:1794-1805. https://doi.org/10.1111/j.1365294X.2012.05538.x

47. Solidoro C, Bandelj V, Bernardi FA, et al (2010) Response of the Venice Lagoon ecosystem to natural and anthropogenic pressures over the last 50 years. Coast Lagoons Crit Habitats Environ Chang 483-511. https://doi.org/10.1201/EBK1420088304

48. Sullivan LJ, Gifford DJ (2004) Diet of the larval ctenophore Mnemiopsis leidyi A. Agassiz (Ctenophora, Lobata). J Plankton Res 26:417-431. https://doi.org/10.1093/plankt/fbh033

49. Tagliapietra D, Sigovini M, Ghirardini AV (2009) A review of terms and definitions to categorise estuaries, lagoons and associated environments. Mar Freshw Res 60:497-509. https://doi.org/10.1071/MF08088

50. Tiselius P, Møller LF (2017) Community cascades in a marine pelagic food web controlled by the nonvisual apex predator Mnemiopsis leidyi. J Plankton Res 39:271-279. https://doi.org/10.1093/plankt/fbw096

51. Vidjak O, Bojanić N, de Olazabal A, et al (2018) Zooplankton in Adriatic port environments: Indigenous communities and non-indigenous species. Mar Pollut Bull 147:133-149.

https://doi.org/10.1016/j.marpolbul.2018.06.055 
52. Waggett R, Costello JH (1999) Capture mechanisms used by the lobate ctenophore, Mnemiopsis leidyi, preying on the copepod Acartia tonsa. J Plankton Res 21:2037-2052.

https://doi.org/10.1093/plankt/21.11.2037

\section{Figures}

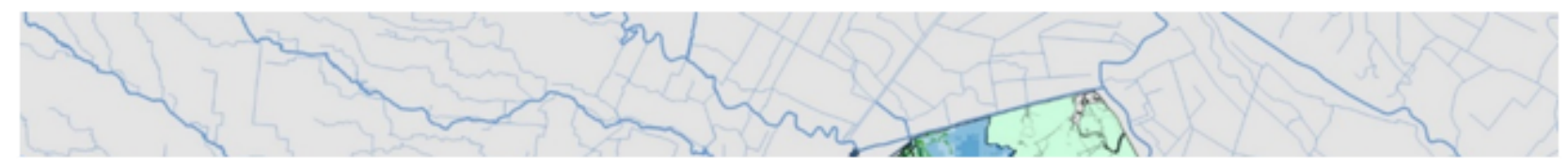

\section{Figure 1}

Study site and sampling stations. Orange dots refer to stations being part of the LTER network, while yellow dots refer to 11 stations being sampled for this study (from Schroeder et al. (2021).

\section{Figure 2}

A) PCoA (Principal coordinates analysis) of environmental parameters colored by sampling month (left) and by location (right). B) Boxplot of Temperature, Salinity and Turbidity measured by a multiparametric sonde 
during sampling activities.

\section{Figure 3}

Relative biovolume of $M$. leidyi in terms of $\mathrm{ml} / \mathrm{m}^{3}$ : A) biovolume of samples where M. leidyi was present, B) Boxplot of biovolume through the year of observation (colors refer to median temperature $\left[{ }^{\circ} \mathrm{C}\right]$ per month), $\mathrm{C}$ ) and at the 16 stations (July-October) (colors refer to median salinity per station).

\section{Figure 4}

Composition of $M$. leidyi gut content (above) and in-situ mesozooplankton community (below) for the 44 samples where the presence of Mnemiopsis was detected. Colors of barcharts indicate taxonomic composition, while colored circles indicate the month of sampling.

\section{Figure 5}

Correlation plot of all taxa (\% based on square-rooted data) of the most abundant copepod species (A, B), mollusk species (C) and other taxa. Pearson's correlations between the two datasets are given in the corresponding color.

\section{Figure 6}

Beta-diversity estimates based on Bray-Curtis similarities plotted on NMDS of Mnemiopsis 'gut content (A), the in-situ mesozooplankton community (B) and of both datasets in a single NMDS plot (C). Colors of points refer to the sampling season or location of each sample. 